Article

\title{
Justice, Anger and Wrath: Tracing the Im/Moral Dimensions of Payback
}

\section{Celia E. Deane-Drummond}

Laudato Si' Research Institute, Campion Hall, University of Oxford, Brewer St., Oxford OX11QS, UK; celia.deane-drummond@campion.ox.ac.uk

Received: 29 July 2019; Accepted: 24 September 2019; Published: 26 September 2019

\begin{abstract}
Martha Nussbaum's Anger and Forgiveness makes explicit claims about the moral valence and irrationality of the desire for payback. This article explores the roots of that desire through an analysis of research on inequity aversion in primates, and the sociocultural developmental context for expressions of anger. It explores the content of different expressions of anger and their relationship to rationality by engaging in the work of Thomas Aquinas. I argue that the desire for payback has biosocial roots in cooperation, and that these habits are prerequisites for the development of human moral sensibilities. However, the explicit desire for payback, like anger in general, is morally ambiguous. Anger may be laudable insofar as it is tied to constructive efforts, but the desire to see another person suffer is in itself morally repugnant. Christian religious interpretations of payback further complicate the narrative, since unappealing instances of this desire are thought by some Christians to be nonetheless justified under the banner of God's wrath.
\end{abstract}

Keywords: payback; inequity aversion; fairness; anger; wrath; morality; Thomas Aquinas; Martha Nussbaum

\section{Introduction: Background}

Martha Nussbaum's book Anger and Forgiveness includes a chapter on anger where she develops a discussion of payback (Nussbaum 2016, pp. 14-56). She is particularly troubled by a defining element of the desire for payback, which is the idea that "it would be a good thing if the wrongdoer suffered some bad consequences somehow," on account of what the person did (Nussbaum 2016, p. 5). Nussbaum also objects to a belief that seems to underlie the desire for payback, which is that payback can restore order to social relationships. She judges that such beliefs can only derive from 'deep rooted but misleading ideas of cosmic balance, and from people's attempt to recover control in situations of helplessness' (Nussbaum 2016, p. 5). Such ideas, according to her argument, are false and irrational, for an offender's suffering cannot, in fact, restore a valued item that has been harmed or lost.

Nussbaum considers a case of rape, where the desire to punish the rapist, on the part of the victim's friend, implies "some type of magical thinking" (Nussbaum 2016, p. 24) because the punishment could never undo the harm that was done (Nussbaum 2016, p. 24). Nussbaum suggests that the idea that payback can even the score with an offender may be part of "our evolutionary endowment" (Nussbaum 2016, p. 24). She notes that literary narratives are also replete with stories where wrongdoers are made to suffer harm in a way that is meant to be aesthetically pleasing to readers. Nussbaum presses home the point that both evolutionary history and aesthetics can be misleading inasmuch as they suggest that it makes sense to have such desires.

What Nussbaum does not do is analyse the relationship between the desire for payback and the desire for fair treatment. She also dismisses rather too readily evolutionary and psychological perspectives on the payback element in anger, which I argue can illuminate the discussion and explain some of the attraction to what she terms the "magical" element of the desire for payback and show 
that it is not necessarily 'irrational' in the way she suggests. On closer examination, therefore, this element may not be quite as dismissible as she presupposes. Further, adjudicating when anger is or is not justifiable, as far as its connection to payback is concerned, becomes more complicated than she implies when particular religious traditions are also brought into the picture.

Nussbaum's thesis has attracted some recent debate among scholars of religion. Jackson (2018) worries that, on Nussbaum's view, forgoing anger becomes a requirement of justice that can be owed to an offender, Diana Cates interprets Nussbaum to say that avoiding anger is simply a requirement of rationality (Cates 2018, p. 779). My own reading of Nussbaum is similar to that of Cates, namely that for Nussbaum, a lack of anger and the desire for payback in anger, is not owed an offender as a matter of justice, but that it is irrational to think in such ways. Cates doubts, as I also do, whether Nussbaum is correct to say that a desire for payback is always predicated on "magical thinking", which a rational person would dispel. There are many religions that make claims about suffering and the restoration of cosmic justice that are very meaningful to the participants. I agree with Jackson when he worries that Nussbaum conflates or merges various categories that need to be distinguished, including anger and hatred, which I will consider later (Jackson 2018, pp. 760-61). While I am more broadly sympathetic to Nussbaum's eudaimonistic philosophical approach than Jackson, he is also perhaps correct to challenge the adequacy of her interpretations of historical events and their consequences (Jackson 2018, pp. 756-58). My own, main critique of Nussbaum is that she pays insufficient attention in her book to animal research that points to some of the functional emotive roots of the desire for payback which carry their own rationality in social evolutionary terms.

In other words, my argument in this paper is that those scholars who want to understand where the desire for payback comes from need to take more account of the social sciences, particularly ethology as well as ethnography, specifically the observation that a sense of fairness among social animals is commonplace and learnt from an early stage of development. When an infringement of the fairness that is expected leads to anger, that anger may involve a desire for attack or for retribution towards those who provoked it. In hierarchical societies such as chimpanzees, striking back would be a risky strategy to adopt if it were directed towards one higher in the social hierarchy, as it would likely escalate into further violence and consequent suffering. By the same token, retribution, also known as payback, can be a risky strategy for humans as well. Anger that is particularly strong and fixated on the punishment of the offender is typically distinguished from ordinary anger and called wrath.

Having identified some of the issues and controversies that surround the desire for payback, this article will introduce some scientific research that illuminates where the tendency for payback may have come from in evolutionary terms, and then, after an excursus into sociocultural treatments of anger which help fill out this account with regard to human communities, ask about the extent to which such tendencies are ethically significant. I suggest that this discussion is illuminated further by paying attention to Thomas Aquinas' nuanced discussion of anger and vengeance. I suggest that, on the one hand, animal studies reveal some good reasons, albeit naturalistic ones, for why the desire for payback may have arisen. On the other hand, Aquinas' discussion helps to draw helpful distinctions between anger and other passions such as hatred in a way that highlights those cases which allow for a rationality in anger.

\section{Inequity Aversion in Primates}

Many primatologists speak less about fairness and more about what they believe is a prelude to a sense of fairness through the concept of inequity aversion that is defined as a strong reaction, under certain conditions, to unequal distributions of goods ${ }^{1}$. First order inequity aversion is that related to unequal distribution of goods for the subject. Second order inequity aversion is that related to the unequal distribution of goods for a partner. Inequity aversion is perhaps more relevant than a

1 This discussion on justice and fairness is developed further alongside a theological account in Deane-Drummond (2019). 
weaker sense of "unfairness" to a discussion of payback, since payback is also a strong reaction to what is perceived to be an unjustified harm. Primate research shows associations between cooperative behaviour more generally and different responses to inequity (Brosnan 2011a). The important point is that inequity comparison is social in nature. The extent of the reaction to inequity between conspecific partners depends on rank, sex, and group identity and may also be related to individual differences. Nevertheless, primates show strong reactions to perceived inequity. A plausible biological explanation is that reacting strongly to inequity has evolutionary advantages in that it encourages individuals to find new partners when a current social relationship is not to their advantage. Such reactions are not necessarily self-conscious; all that seems to be required is the recognition of another individual as a potentially rewarding social partner, which seems to be very widespread within the animal kingdom, including invertebrates (Steiger et al. 2008). Current feelings for partners known as attitudinal reciprocity may also play a role here (Schino and Aureli 2010).

Sarah Brosnan has proposed that there is an evolutionary link between cooperation and inequity aversion. Based on this hypothesis one would predict that (1) inequitable outcomes affect cooperation, (2) negative responses to inequity are situated in the context of cooperation, and (3) cooperative species are more sensitive to inequity (Brosnan 2011a, p. 4). All three hypotheses have been tested in experimental protocols by Brosnan's research team and others, providing reasonable evidence for a strong evolutionary link between cooperation and inequity aversion.

An awareness of the intention of the actors is significant (Brosnan 2011a, p. 4). It is well documented that humans, for example, will react more negatively to inequity when they know it has arisen from a deliberate choice rather than from a random chance event. The desire for payback, in particular, is sensitive to intentions: there is less inclination to want to harm an offender if the harm the offender caused is perceived by the victim as accidental, rather than intended. While reactions to inequity can develop among primates (and other animal species) without any specific awareness of the intentions or motives of their partner, primates do seem to exercise this ability in some cases as well. For example, primates will respond more negatively to an experimenter who deliberately drops a reward than to drops that appear to be accidental (Call et al. 2004).

It is perhaps important to qualify these statements in that inequity aversion among primates only shows up when particular conditions prevail. There are no reactions to inequity in primates where there is simply an unequal distribution of goods; in all cases, a task seems to be required prior to getting the goods as rewards. Chimpanzees, for example, in Brosnan's research, who failed under other circumstances to respond to an unequal distribution of rewards did respond when this was part of a task to be rewarded. One possible explanation is that performing a task at the same time mimics joint activity, so subjects expect a more equitable outcome. Desire for payback among animals is also set in the context of particular social relationships. In addition to factors of sex, rank, and group identity, the experimental design of the tasks and individual differences may play a role. Squirrel monkeys, which share the same phylogenetic family as capuchins, cooperate less, and in experiments, they did not react to inequity (Talbot et al. 2011). They completed their tasks regardless of whether their partners received a reward. What looks like an exception to the rule was found in the tamarins, who are cooperative breeders, that is, both males and females collaborate in rearing the young. Tamarins were insensitive to inequity when the partners in the pair were male and female (Neiworth et al. 2009). Brosnan concludes that in cases where the partnership is a very close interdependence, inequity aversion would be a disadvantage in evolutionary terms. By the same token, the desire for payback may also be less common where it involves a close partner.

Can inequity aversion across a wide range of species be conflated with a general sense of "fairness"? The scientific debate on this topic is complex, but overall still supports a biosocial basis for payback. Those working with primates generally resist equating inequity aversion and fairness, especially when it comes to the most basic primary form of inequity aversion. This is because a sense of fairness is understood to be a higher order reflection on what it would be reasonable to expect in a given situation, whereas a response to first order inequity is a much simpler comparative measure. As noted above, 
scientists speak of second order inequity aversion, in which an individual is sensitive to a partner getting less than the individual for the same task. This secondary aversion is explained in evolutionary terms as being based on the need for long-term cooperation and not just short-term gain. "Fairness" implies something even more advanced in reflective terms, namely, a judgment that contributions must be balanced according to an agreed-upon standard of fairness, which is violated when inequity occurs.

Inequity aversion in its primary and secondary forms could be thought of as the behavioural prerequisite to higher order fairness in that without inequity aversion, it would be hard to believe that a sense of fairness could emerge in a society. Is it ever reasonable to call hints in the behaviour of animals a sense of "fairness", in so far as it is considered in light of the specific perspective of those animal societies? Based on the research on inequity aversion discussed above, Brosnan is prepared to use the language of "morality" (Brosnan 2011b, pp. 23-30), but she hesitates to use the term "fairness".

Brosnan and de Waal suggest that "The hallmark of a human sense of fairness is the idea of impartiality; that is, human fairness or justice is based on the idea that appropriate distributions are to be made to everyone within the community, not just to a few individuals, and, in particular, not just to oneself. Thus, outcomes are judged according to a standard or ideal" (Brosnan and de Waal 2014, p. 1251776). Here, fairness and justice seem not to be distinguished. I would describe the authors' definition of fairness as more appropriate to the idea of justice. In human societies, it is helpful to distinguish fairness as a more generalized and perhaps emotive sense, while even in the most minimalist and superficial sense, justice implies relating to others according to specific agreed-upon rules. A just person is necessarily a fair person, but justice, which requires making reasoned judgments in order to give each person their due, is not necessarily characteristic of a fair person. ${ }^{2}$

Ethologist Marc Bekoff and philosopher Jessica Peirce have discussed social rules of animal societies in their book Wild Justice (Bekoff and Peirce 2009). "Fair play" as articulated by Bekoff is good for all parties, including the most vulnerable. Play behaviour is like inequity aversion in that it varies across species and in response to the specificity of particular relationships according to rank, sex, kin, and non-kin. There are inter-specific variations worth considering. While a sense of fairness is evident in studies with canids, for example, in that there seem to be specific rules laid down for behaviour rather than the employment of a simple comparative measures as is the case with inequity aversion, wild "justice" as described by the authors, seems to lack a reflective and deliberative concern for the other that is integral to human justice. The possibility of wild justice arises only when a more general notion of fairness in social animals is accepted as the reference point (Deane-Drummond 2015).

Bekoff and Pierce define what they term a "justice cluster" as those observable behaviours found in social animals in relation to a generalized sense of fairness, including "a desire for equity and a desire for and capacity to share reciprocally", reactions to equity in expressions of "pleasure, gratitude and trust", and reactions to inequity in expressions of "retribution, indignation and forgiveness" (Bekoff and Peirce 2009, p. 113).

As I mentioned above, many biologists prefer to call such expressions of "fairness" inequity aversion, rather than using the more anthropomorphic language of "wild justice". Bekoff has defended such language in a number of articles (Horowitz and Bekoff 2007). In as much as this language offers a heuristic tool to understand other animal societies better, I believe it is justified, although of course, a layperson must take care not to assume that what fairness, justice, indignation, or even forgiveness means for animal societies is necessarily in direct continuity with what the terms mean in human societies. Rather than close laboratory investigations, the primary tool, in this case, is cognitive ethology, a way of studying animal behaviours in their natural settings. Just as biologists are hesitant to use the term "freedom" for other animals, preferring the more generic term "agency", until comparatively recently, most biologists studying social animals hesitated to use the term "justice" when referring to

2 A full discussion of a theology of justice, including that discussed in Aquinas, is outside the scope of this paper, but I have discussed justice as virtue in some detail elsewhere, such as Deane-Drummond (2014) and developed further in Deane-Drummond (2019). 
the cluster of behaviours that seem to be connected with a generalized sense of fairness. Bekoff and Pierce are prepared to go further than many biologists in using the term "wild justice" based on the following evidence: (a) a keen sense of justice as fairness is universal in humans; (b) even very young babies have a strong sense of fairness, which is a form of social evaluation even without symbolic language; and (c) indicators from direct observation of animal behaviour. While they press for the idea of evolutionary continuity, they acknowledge that justice is not necessarily the same in different species or exactly the same for conspecifics in different contexts.

Is it reasonable to interpret the human desire for payback, which purportedly aims at justice, as being closely related to inequity aversion found in primates? If it is, then something like payback is likely to be characteristic of a wide range of social animals, and so have deep roots in evolutionary time. Further, the insight that inequity aversion is strongly linked with the ability to cooperate implies that there are complex reasons why the desire for payback is part of a suite of goods that are prerequisites for cooperation in the human community. It seems mistaken, then, to say that the desire for payback is based in "magical thinking", as Nussbaum proposes. I would argue, however, that it is problematic to talk about "payback" or "justice" in societies other than human ones because these terms also imply a measure of deliberation and an assessment of goals, even if some of their emotive roots are shared in common with many other species. The difficult question to answer concerns how far and to what extent cultural factors can moderate, exaggerate or override biologically rooted desires in human communities. Evolutionary anthropologists generally prefer to speak of biosocial or biocultural evolution, thus highlighting how difficult it is to separate or distinguish these different elements (Ingold and Palsson 2013). The ability of humanity to imagine the future and operate in semiotic worlds sets humans apart from other primates, even if there are also clear lines of continuity (Marks 2020).

\section{Evolutionary Roots of Anger and Payback}

Charles Darwin's Expression of the Emotions in Man and Animals sought to identify the way in which emotional states, such as anger, and related behaviours, such as aggression, facilitate survival. Darwin also pursued the question of why human beings still experience emotions that may no longer be useful in a biologically adaptive way, as they must have been in earlier in evolutionary history. He was concerned with the basic involuntary physiological responses that appeared to be associated with emotions. He noted, for example, that hairs, feathers and other dermal appendages are raised involuntarily "under the excitement of anger or terror: more especially when these emotions are combined, or quickly succeed each other" (Darwin 1872, p. 95). The animal thus excited appears larger or more frightening to any opponent or competitor in a way that has survival value. Darwin's investigations still inform contemporary scientific understandings of the emotions and therefore influences the idea that anger is a positive emotion and contributes to survival.

Many contemporary psychological studies have also informed the way that people think about emotions. Some studies have focused, for example, on facial expressions in humans that are thought to identify the presence of anger, fear, happiness, sadness, surprise and disgust. Others have focused on neurobiology. Both fear and anger are thought to involve identifiable neural pathways that centrally engage the amygdala region of the brain (Haidt and Morris 2009).

The philosopher Rom Harré has pressed hard for the significance of constructivist understandings of the emotions as defined by specific cultural contexts. While he does not deny their biological basis (Harré 1988), he refuses to privilege the biological aspect. For him, understanding emotion as primarily physiological and primitive arises because of a human propensity for (1) contrasting emotion with volition and diminished responsibility (2) contrasting emotion with reason; (3) associating emotion with being brutish and animalistic and opposed to human reasoning faculties that are viewed as more sophisticated. On Harré's view all these contrasts are problematic in themselves, but also because this way of thinking about emotion fails to reflect the significant role that culture plays in the construction of human emotions. 
The challenge, therefore, is to find a way to discuss the evolutionary and biological aspects of emotion without reducing human emotions, in particular, to their evolutionary roots or their physiological aspects and thereby diminishing human responsibility for them. Darwin did not categorize emotions as primary or secondary, but many subsequent biologists have placed anger in the category of primary emotion, implying that it is involuntary. The challenge is also to avoid what Frans de Waal refers to as a "veneer theory" of human emotion and morality, which treats moral emotions as if they arose in humans only, and apart from the process of evolution (De Waal 2006). Part of the difficulty, it seems to me, is that when biologists refer to anger in animal societies, it is not always clear to what extent they think that this anger is also learned. There has to be a way to give credit to the biological aspects of anger without reducing anger to these aspects in the way that Harre finds so offensive. At the same time, treating those biological aspects as simple physiological expressions of what is happening in a cultural context and in the construction of culture, in the way that Harré tries to do, is far too thin in biological terms, as it seems to neglect the functional aspects of biological explanations and the interrelationships between the biological and the cultural noted above.

One way to begin to navigate through such a puzzling set of arguments is through developmental and cultural psychological research. This research has shown that, by two years of age, children can pick up different states of arousal in others, for example by observing expressions on faces (Wilden 2016). Emotions of happiness, sadness and anger can be detected. But until children reach four years old, they cannot distinguish anger from disgust. Developmental studies with rhesus monkeys demonstrated that when infants are raised with their peers rather than their mothers, a whole suite of biological and social malfunctions arise, including significantly higher levels of stress, anxiety and aggression (Dettmer et al. 2014). Both of these results imply an intertwined relationship between the biological and the cultural, rather than rendering one primary or secondary in importance. The desire for payback, therefore, may also depend in a significant way on prior developmental experiences.

Research on adults living in Batek hunter-gatherer societies has shown low aggression and violence between adults, which seems to be encouraged by specific training at an early age (Endicott and Endicott 2014). In this case, babies between one and two years old who expressed anger were separated without comment or at older ages told not to annoy others. The initial training strategy was to ignore the behaviour rather than draw attention to it. The point is not that absence of aggression is simply culturally conditioned. Rough and tumble play with peers, which occurs in groups of many social animals, is likely to have an evolutionary function of facilitating the learning of the art of restrained aggression and accurate sensitivity to other social cues (Fry 2014, pp. 178-83).

There are cultural differences between societies, which influence the extent to which anger and the desire for payback are expressed and how they are expressed. Research in different cultural contexts has shown that in the USA anger is an accepted part of expressions of autonomy and assertiveness, while in Tibet, a similar emotion known as lung lang is viewed as a bad feeling that is at odds with Buddhist conceptions of compassion and living in non-harmful ways (Mesguita et al. 2016, p. 393). Mesquita et al. also compared Japanese and American subjects, and their study showed that while individuals in both cultures experienced anger or an equivalent, the emotions that were more in line with central goals and values of that culture were considerably more frequent and intense. The researchers also showed that immigrants demonstrated emotional patterns that were, to some extent, a blend of their culture and the new culture they adopted.

The same researchers showed that anger is more likely to be triggered in cultures that stress the value of independence rather than interdependence. In a Japanese context, anger is expressed as nodding, smiling and ruminating in $55 \%$ of cases. In American and Belgian contexts, anger is expressed in the form of blaming the other person in 43\% of the cases (Mesguita et al. 2016, p. 398). This research raises the issue of how far specific emotions might be related to group identity. Reactions as an individual can be distinguished from reactions that occur through identification as a group member through a process involving depersonalization (Smith and Mackie 2016). In these situations, people do not react emotionally just as individuals, but rather within the context of a social group that 
has become integral to their group identity. An offence against one of the group members therefore can elicit angry emotive responses as if the offence were directed against them as individuals. In such cases, "the group becomes in a real sense an aspect of the person's psychological self" (Smith and Mackie 2016, p. 413).

Whereas angry and aggressive gestures encourage angry and aggressive responses, conciliatory gestures seem to encourage conciliatory responses. Michael McCullough and colleagues speculate that, just as there may be an evolutionary advantage to individuals being able to take revenge on those whose action has harmed them, there is also likely a biological advantage among the same individuals in being able to reconcile with transgressors who retain some social value, despite the harm they caused (McCullough et al. 2014).

The desire for payback is complicated. Its emotive roots in inequity aversion suggest that it could only have emerged in cooperative communities. Yet, densely cooperative communities have learnt to overcome such tendencies and act differently in ways that effect reconciliation. Among primates, for example, frequent affirmative interactions and gestures after conflict seem to be universal (Deane-Drummond 2019). In a longitudinal study with over three hundred human participants who had been harmed by a partner, conciliatory gestures on the part of the transgressor, such as apologies or offers of compensation, were associated with elevations of victims' perceptions of offenders' value as partners, as well as their lower risk of recidivism (McCullough et al. 2014, p. 11211). The participant pool for this study comprised undergraduate psychology students whose anger was measured through self-report, following recall of the transgression event, and an interview that involved the use of anger words and facial gestures (McCullough et al. 2014, p. 11214). McCullough recognises that human forgiveness is considerably more complex compared to reconciliation behaviours among other animals, but in humans, the victim's perception of the elevated value of the partner increases the likelihood of forgiveness, as well.

\section{Anger as Moral Passion in Aquinas}

One of the most common triggers for anger is a sense of inequity or insult. Aristotle defined anger as "as an impulse, accompanied by pain, to a conspicuous revenge for a conspicuous slight directed without justification towards what concerns oneself or towards what concerns one's friends. If this is a proper definition of anger, it must always be felt towards some particular individual, e.g., Cleon, and not 'man' in general" (Aristotle 2016, Book II.2). Anger arises in an individual on account of the fact that a particular individual has done or is about to do something to him or his own. Enmity and hatred are not necessarily directed towards a particular individual.

Aristotle's perception is that anger is bound up with a sense of injustice and the ideas of unjustified harm and outrage (Fortenbaugh 1969, p. 165). More specifically, anger implies an evaluative judgment that harm, in the form of injustice, has been done, along with a desire to pursue a particular end by taking revenge. Aristotle's definition of anger proposes further that anger "must always be attended by a certain pleasure- that which arises from the expectation of revenge" (Aristotle 2016, Book II.2). Thus, anger is experienced as a complex mixture of both pain over an injury and pleasure at the thought of revenge, which is the classic language used for payback.

Aquinas' position on anger is influenced by Aristotle's perception of anger as a social passion, as well as the theological discussion of God's anger in the work of Augustine. His analysis helps to tease out different strands within anger that are important for an understanding of the meaning and significance of payback in a way that Nussbaum does not develop adequately in her account. One of Aquinas' key ideas was that the irascible appetite (derived from anger, ira) was in both the rational and the sensible appetites, the former associated with reasoning and the latter in common with other 
animals. ${ }^{3}$ This twin reference is helpful in that it provides a further way to connect the ethological discussion highlighted above and sociocultural influences which shape the particular way anger comes to be understood in a given community as that which occurs in accordance with specific reasons, In other words, anger involves rational thought, but there are also aspects of anger as passion that humans share with non-rational animals. Aquinas considers anger to be a contending appetite, along with hope and despair, fear and daring, which arise only when obstacles or other difficulties present themselves. Aquinas echoes Aristotle when he says, more specifically, that anger is a response to a difficulty in the form of a perceived injury, which is experienced as painful. At the same time, anger is a response to images of the possibility of revenge, which are experienced as pleasurable (Aquinas 1963, Qu. 46.1). Given that anger can include multiple passions, Aquinas considers whether or not it is discrete. He concludes that the convergence of passions in anger, most notably sorrow and hope, does not rule out its specificity. It is this complexity in anger as having two different aspects, one of which is disagreeable, and one which is agreeable, which marks it out as distinct from love or hate, which are directed toward what is perceived as good and experienced as pleasant, or toward what is perceived as evil and experienced as repugnant (Aquinas 1963, Qu. 46.2). ${ }^{4}$ He follows Aristotle in saying that anger can be reasonable. However, anger can also be an obstacle to good reasoning (Aquinas 1963, Qu. 48.3). He also includes some reference to the way that hope for vengeance can be hard to align with rational thought (Aquinas 1963, Qu. 46.4). More precisely he claims, following Aristotle, that 'anger listens somewhat to reason insofar as reason denounces the injury inflicted, but listens not perfectly, because it does not observe the rule of reason as to the measure of vengeance (vindictam). Anger, therefore, requires an act of reason, and yet proves a hindrance to reason' (Aquinas 2012, Qu. 46.4). This complexity is important to understand in working out how far and to what extent the desire for payback (or, as Aquinas prefers, vengeance) is reasonable. Aquinas concludes, sensibly in my view, that the answer is not simple; desire in anger can be responsive to reasoning, but it also tends also to distort that very reasoning.

Along with Aristotle, Aquinas allows for the fact that an inclination to become overly angry can be inherited from one's parents (Aquinas 1963, Qu. 46.5). Although he had no knowledge of the complex interrelationship between natural and cultural endowments, and different aspects of biological and cultural evolution, perhaps remarkably, he was aware that specifically human inclinations towards anger can arise, in part, from specific patterns of inheritance. At the same time, in his judgment, anger is capable of being moderated, so "on the part of the bodily temperament", a person "does not naturally excel others either in anger or in any other passion, on account of the moderation of his temperament" (Aquinas 2012, Qu. 46.5). Some animals, on the other hand, will be "excessively inclined" to a specific passion, and he names the hound as the animal most associated with anger! (Aquinas 2012, Qu. 46.5). We know, however, that dogs can be bred for temperament, and they can also be trained. Moreover, anger among animals is not confined to hounds. But Aquinas does not discuss such details.

Aquinas distinguishes anger from hatred by describing anger as a passion that aims at something good (namely just vengeance or payback), in a way that hatred does not. The Stoics thought that hatred was a developed form of anger, but Aquinas disagreed, naming hatred as a distinct passion, even if anger could be preliminary to its formation. ${ }^{5}$ Aquinas considered it possible for anger to give way to mercy, whereas this is not possible with hatred, on his view. Furthermore, once justice is done the angry man is appeased in a way that is not possible in hatred. However, if one is dealing with extreme anger, the inclination to give way to mercy is likely to be small (Aquinas 1963, Qu. 46.6).

3 Scotus also similarly distinguished the two kinds of appetite and allowed irascible appetites to be in both forms. Like Aquinas he also divided the irascible appetite into fear/courage; despair/hope and anger as such, which had no opposite. See Perreiah (1998, pp. 328-31).

4 He also seems to follow Aristotle in naming anger here as being directed against someone, rather than being more diffuse. 5 On this point, and on a fuller discussion of hatred and other related passions in Aquinas see Green (2007). 
Aquinas follows St John Damascene and St Gregory of Nyssa in defining three different types of anger, which name the ways in which anger can be progressively intensified. This is another helpful elaboration of the complexity of anger in human communities and its relationship to payback. Anger which is quickly aroused is called wrath. Anger which is more enduring and remembered over a long time is called ill-will, which has the same root in Latin as abiding. And anger that is overly concerned with revenge (or payback) is called rancour, which will only be satisfied when punishment is enacted (Aquinas 1963, Qu. 46.8). Once Aquinas moves to his discussion on the motives and remedies for anger (Aquinas 1963, Qu. 47), he considers additional cases not considered by Aristotle, such as the anger of God and anger on behalf of others. In the first case, he suggests that God does not become angry in the same way that humans do; rather, God's anger is simply the result of just judgment and a will to punish sin (Aquinas 1963, Qu. 47.1). In the second case, he expands the circle of people who are affiliated with us, beginning, interestingly, with close family, and then extending to friends and those who share "at least the same human nature" (Aquinas 1963, Qu. 47.1). Although the practice of extensive benevolence is given the label "altruism" by biologists, its extent among nonhuman animals is debated. Helpfulness toward others who are not kin from whom an animal would likely benefit is sporadic (Pedersen et al. 2013).

For Aquinas, following Aristotle, the primary motivation for anger is a slight, expressed as contempt, spite not insolence. The injuries inflicted are greatest when they are perceived as deliberate acts of malice, and for Aquinas less deliberative acts, which are perceived as being done in ignorance or under the influence of a strong passion, either do not provoke anger, "or at least not violently so" (Aquinas 1963, Qu. 47.2). As in the cases of work among primates, it is the intention of the actor that is important in terms of the likely reaction of the one who has been offended or injured. In cases of injury committed through ignorance or strong passion, mercy and forgiveness are more likely to present themselves as viable possibilities. Interestingly, Aquinas was aware that while unjustified contempt provokes anger, conciliatory gestures by those who repent of their wrongdoing, confess it, humble themselves and ask pardon "turn away anger" (Aquinas 1963, Qu. 47.4). The particular virtues of clemency and gentleness together help to moderate anger, as he explains: "The passion of anger provokes a man to punish over-severely, and though it is the function of clemency to mitigate punishment, this activity can be blocked by anger. It is the function of gentleness to restrain anger, and in doing so it runs with clemency to the same effect" (Aquinas 1971a, Qu. 157.1). The contrary of gentleness is wrath (wrath can name a passion or a vice), while the contrary of clemency is cruelty.

Aquinas becomes explicit about the difficulty of moderating the desire for revenge in a discussion of brawling, where anger impairs judgment and the brawling that follows looks like foolishness. The capacity to think clearly and form rational judgments is often distorted in anger, which entails that forms of injustice, such as defamation, can arise through anger (Aquinas 1974, Qu. 72.4). Thus, importantly, even though anger often arises in the context of a concern for justice, forms of injustice can follow from its improper operation. Anger can also be used more positively in order to foster actions of courage, although for Aquinas, it is the attacking mode of courage rather than the enduring mode of courage that requires anger, since in the latter case, reason alone is sufficient (Aquinas 1975, Qu. 123.11).

Both Aquinas and Scotus accepted that the desire for revenge could lead to the enactment of revenge and seemed to affirm the enactment as a valid possibility for humans, whereas other scholars assumed that all vengeance is properly left to God. Scotus' acceptance of the validity of vengeance is, for Perreiah, "inconsistent with the Christian principle that vengeance is a function of divine justice" (Perreiah 1998, p. 340). Aquinas argued, to the contrary, that vengeful action could, under strict conditions, express virtue, most notably the virtue of justice. It was not simply to be regarded as a divine prerogative (Aquinas 1971b, Qu. 108.1). For Aquinas, the focus an act of vengeance is the most important aspect to consider. If the focus is on "the evil done to the recipient", then the anger is unlawful. However, if the focus of anger is on the good to be accomplished through vengeance-on the restoration of justice - then vengeance is permitted, if it accords with the rule of justice and the 
person who inflicts it (ideally an official) is exercising a God-given power, rather than arrogating to himself what is rightfully God's (Aquinas 1971b, Qu. 108.1). Where a community has done wrong, then the whole community is subject to punishment, but not in cases where only a part of a community has committed a crime. In some situations, sparing punishment for the sake of not giving scandal to those who are innocent may be the better course of action.

At the same time, because Aquinas believed that children and animals were the property of their parents or owners, he argued that it is permissible to punish children, slaves and animals as a means of exacting punishment on the parents (Aquinas 1971b, Qu. 108.4). Such a view is clearly unacceptable to present sensibilities which rightly reject the notion of slavery and give rights to children and those who are innocent.

For Thomas, anger is therefore permissible within certain boundaries. Indeed, anger is sometimes required. Its total absence when it should be present shows a lack of virtue (Aquinas 1971a, Qu. 158.8). Overall, Aquinas paints a picture of anger as a positive passion, a disposition toward which can be cultivated as a virtue (Lombardo 2011, pp. 250-51). Meekness, also significant in this context, names a virtue and the expression of virtue. The virtue makes a person less prone to excess (Aquinas 1971a, Qu. 157.3, Qu. 157.4).

\section{Tentative Conclusions}

In order to understand and evaluate the desire for payback, which is central to at least some forms of anger, I argued that rather more needs to be accomplished by way of biocultural analysis and theological interpretation. Martha Nussbaum has dismissed the desire for payback rather too readily in saying that it amounts to a form of "magical thinking" or a reflection of "narcissism". On the one hand, research with primates has shown that sensitivity to inequity has co-evolved with the ability to cooperate, which can then give rise to both helpful and socially harmful behaviours. While the desire for payback cannot be equated with aversion to inequity, it often arises in a similar context of a perceived violation of cooperative social practices. On the other hand, Aquinas is useful in that he makes many valuable distinctions, which reveal the complexity of human anger and allow him to be specific about the elements and the instantiations of anger that are consistent with morality and those that are not. He shows that this level of specificity complicates the moral evaluation of anger. It also complicates the assessment of the desire for payback. His analysis shows that anger and the desire for payback reflect an inclination, on the part of humans, to set right violations of justice and reinforce specific cultural norms on which justice depends-an inclination that can be informed by good judgment.

Therefore, I part company with Nussbaum, who views the desire for payback as a reflection of irrationality and fantasy. Rather, this desire is also a reflection of the social nature of humans (and other animals) and the biological need for cooperation. The desire for reconciliation and the use of conciliatory gestures in the wake of a perceived injury is a reflection of the same conditions.

The specific historical and cultural milieu will affect the extent to which anger and associated desires for payback are felt on a sensory level and not simply in the form of cerebral or semiotic ideas. While those ideas may be at work in anger and some of them can be expressed in constructive theological accounts, in my view, they are more likely to be integrated into the biosocial roots of anger and payback, rather than a veneer added to or on top of those desires. Aquinas gives a rich account of anger that includes reflection on God as the guarantor of cosmic balance or justice. He distinguishes between the human desire for revenge and the notion of wrath and revenge in God in response to an infringement of God's holiness. He rejects the view, common at the time, that it is only permissible for God to take revenge. To show that human anger is sometimes appropriate and even required, he traces the motivations behind an intention to seek revenge and shows that the focus of a given instance of anger is of particular moral significance. If the focus of the anger is primarily on the punishment and pain to be inflicted on an offender, it needs to be checked. If the focus is primarily on the good to be realized in punishing the offender, the anger is more consistent with virtue. The threshold of moral 
permissibility is exceeded when anger makes a person prone to sin from a lack of rational consideration of his actions.

In sum: payback is a complex desire that can be felt and expressed in both virtuous and non-virtuous ways. A great deal of discernment is required to repeatedly apprehend the correct way of desiring payback, such that one becomes disposed to desire it well. Trying to understand what this desire is, where it comes from, and how best to deal with it provides a rich territory for engaging philosophical and theological ideas along with the findings of the natural and social sciences.

Funding: Aspects of this research were supported by a research grant entitled Developing Virtues in the Practice of Science from the Templeton Religion Trust, TRT0088, that supported a research leave period for the author from the University of Notre Dame held at Durham University, UK, from 2018-2019.

Acknowledgments: The author would like to thank Diana Cates for the invitation to contribute to this special issue and for helpful feedback and encouragement during the writing process.

Conflicts of Interest: There are no conflicts of interest.

\section{References}

Aquinas, Thomas. 1963. Summa Theologiae, Fear and Anger. Edited by John Patrick Reid. London: Blackfriars, vol. 21, pp. 1a2ae 40-1a2ae 48.

Aquinas, Thomas. 1971a. Summa Theologiae, Well Tempered Passion. Translated by Thomas Gilby. London: New Blackfriars, vol. 44, pp. 2a2ae 155-2a2ae 170.

Aquinas, Thomas. 1971b. Summa Theologiae, Virtues of Justice in the Human Community. Translated by Thomas Charles O’Brien. London: New Blackfriars, vol. 41, pp. 2a2ae 101-2a2ae 122.

Aquinas, Thomas. 1974. Summa Theologiae, Injustice. Translated by Marcus Lefébure. London: New Blackfriars, vol. 38, pp. 2a2ae 63-2a2ae 79.

Aquinas, Thomas. 1975. Summa Theologiae, Courage. Translated by Anthony Ross, and P. G. Walsh. London: Blackfriars, vol. 42, pp. 2a2ae 123-2a2ae 140.

Aquinas, Thomas. 2012. Summa Theologiae, Prima Secundae. Translated by Fr. Laurence Shapcote. Edited by John Mortensen and Enrique Alarcón. Lander: The Aquinas Institute, pp. 1-70.

Aristotle. 2016. Rhetoric. Translated by W. Rhys Roberts. Adelaide: University of Adelaide, Available online: https://ebooks.adelaide.edu.au/a/aristotle/a8rh/book2.html (accessed on 20 May 2019).

Bekoff, Marc, and Jessica Peirce. 2009. Wild Justice: The Moral Lives of Animals. Chicago: University of Chicago Press.

Brosnan, Sarah F. 2011a. A Hypothesis of the Co-Evolution of Cooperation and Responses to Inequity. Frontiers in Neuroscience 5: 43. [CrossRef] [PubMed]

Brosnan, Sarah F. 2011b. An Evolutionary Perspective on Morality. Journal of Economic Behavior and Organization 77: 23-30. [CrossRef]

Brosnan, Sarah F., and Frans de Waal. 2014. Evolution of Responses to (Un)Fairness. Science 346: 1251776. [CrossRef] [PubMed]

Call, Josep, Brian Hare, Malinda Carpenter, and Michael Tomasello. 2004. 'Unwilling' versus 'unable' chimpanzees understanding of human intentional action. Developmental Science 7: 488-98. [CrossRef] [PubMed]

Cates, Diana. 2018. You Deserve to Suffer for What You Did. Journal of Religious Ethics 46: 771-82. [CrossRef]

Darwin, Charles. 1872. Expression of the Emotions in Man and Animals. New York: Appleton and Company.

Deane-Drummond, Celia. 2014. The Wisdom of the Liminal: Evolution and Other Animals in Human Becoming. Grand Rapids: Eerdmans.

Deane-Drummond, Celia. 2015. Natural Law Revisited: Wild Justice and Human Obligations to Other Animals. Journal for the Society for Christian Ethics 35: 159-73. [CrossRef]

Deane-Drummond, Celia. 2019. Theological Ethics through a Multispecies Lens: Evolution of Wisdom Volume 1. Oxford: Oxford University Press, in press.

Dettmer, Amanda M., Stephen J. Suomi, and Katie Hinde. 2014. Nonhuman Primate Models of Mental Health: Early Life Experiences Affect Developmental Trajectories. In Ancestral Landscapes in Human Evolution: Culture, Childrearing and Social Wellbeing. Edited by Darcia Narvaez, Kristin Valentino, Agustin Fuentes, James McKenna and Peter Gray. New York: Oxford University Press, pp. 42-58. 
De Waal, Frans. 2006. Morally Evolved: Primate Social Instincts, Human Morality, and the Rise and Fall of 'Veneer Theory'. In Primates and Philosophers. Edited by Stephen Macedo and Josiah Ober. Princeton: Princeton University Press, pp. 1-80.

Endicott, Karen L., and Kirk M. Endicott. 2014. Batek Childrearing and Morality. In Ancestral Landscapes in Human Evolution: Culture, Childrearing and Social Wellbeing. Edited by Darcia Narvaez, Kristin Valentino, Agustin Fuentes, James McKenna and Peter Gray. New York: Oxford University Press, pp. 108-25.

Fortenbaugh, William. 1969. Aristotle: Emotion and Moral Virtue. Arethusa 2: 163-85.

Fry, Douglas P. 2014. Environment of Evolutionary Adaptedness, Rough and Tumble Play, and the Selection of Restraint in Human Aggression. In Ancestral Landscapes in Human Evolution: Culture, Childrearing and Social Wellbeing. Edited by Darcia Narvaez, Kristin Valentino, Agustin Fuentes, James McKenna and Peter Gray. New York: Oxford University Press, pp. 169-88.

Green, Keith. 2007. Aquinas on Attachment, Envy and Hatred in the "Summa Theologica". Journal of Religious Ethics 35: 403-28. [CrossRef]

Haidt, Jonathan, and James P. Morris. 2009. Finding the Self in Self-Transcendent Emotions. Proceedings of the National Academy of Sciences of the United States of America 106: 7687-88. [CrossRef] [PubMed]

Harré, Rom. 1988. The Social Construction of Emotions. Oxford: Wiley/Blackwell. First published 1986.

Horowitz, Alexandra, and Marc Bekoff. 2007. Naturalizing Anthropomorphism: Behavioral Prompts to Our Humanising of Animals. Anthrozoos 20: 23-35. [CrossRef]

Ingold, Tim, and Gisli Palsson. 2013. Biosocial Becomings: Integrating Social and Biological Anthropology. Cambridge: Cambridge University Press.

Jackson, Timothy P. 2018. Not Far from the Kingdom: Martha Nussbaum on Anger and Forgiveness. Journal of Religious Ethics 46: 749-70. [CrossRef]

Lombardo, Nicholas E. 2011. The Logic of Desire: Aquinas on Emotion. Washington, DC: Catholic University of America Press.

Marks, Jon. 2020. Continuities and Discontinuities in Human Evolution. In Theology and Evolutionary Anthropology: Dialogues in Wisdom, Humility and Grace. Edited by Celia Deane-Drummond and Agustín Fuentes. London: Routledge, in press.

McCullough, Michael E., Eric J. Pedersen, Benjamin A. Tabak, and Evan C. Carter. 2014. Conciliatory Gestures Promote Forgiveness and Reduce Anger in Humans. Proceedings of the National Academy of Sciences of the United States of America 111: 11211-16. [CrossRef] [PubMed]

Mesguita, Batja, Jazefien De Leersnyder, and Michael Bioger. 2016. The Cultural Psychology of Emotions. In Handbook of Emotions, 4th ed. Edited by Lisa Feldman Barrett, Michael Lewis and Jeannette M. Haviland Jones. New York: Guildford Press, pp. 393-411.

Neiworth, Julie J., Elizabeth T. Johnson, Katherine Whillock, Julia Greenberg, and Vanessa Brown. 2009. Is a Sense of Inequity an Ancestral Primate Trait? Testing Social Inequity in Cotton Top Tamarins (Saguinus Oedipus). Journal of Comparative Psychology 123: 10-17. [CrossRef] [PubMed]

Nussbaum, Martha. 2016. Anger and Forgiveness: Resentment, Generosity and Justice. New York: Oxford University Press.

Pedersen, Eric, Robert Kurzban, and Michael McCullough. 2013. Do Humans Really Punish Altruistically? A Closer Look. Proceedings of the Royal Society Biological Sciences 280: 20122723. [CrossRef] [PubMed]

Perreiah, Alan R. 1998. Scotus on Human Emotions. In Franciscan Studies 56, Essays in Honor of Dr. Girard Etzkorn. Allegany: St. Bonaventure University, pp. 325-45.

Schino, Gabriele, and Filippo Aureli. 2010. Primate Reciprocity and Its Cognitive Requirements. Evolutionary Anthropology 19: 130-35. [CrossRef]

Smith, Eliot R., and Diane M. Mackie. 2016. Intergroup Emotions. In Handbook of Emotions, 4th ed. Edited by Lisa Feldman Barrett, Michael Lewis and Jeannette M. Haviland Jones. New York: Guildford Press, pp. 412-23.

Steiger, Sandra, Ragna Franz, Anne-Katrin Eggert, and Josef K. Müller. 2008. The Coolidge Effect, Individual Recognition and Selection for Distinctive Cuticular Signatures in a Burying Beetle. Proceedings of the Royal Society B: Biological Sciences 275: 1831-38. [CrossRef] [PubMed] 
Talbot, Catherine F., Hani D. Freeman, Lawrence E. Williams, and Sarah F. Brosnan. 2011. Squirrel monkeys' response to inequitable outcomes indicates a behavioural convergence within the primates. Biology Letters 7: 680-82. [CrossRef] [PubMed]

Wilden, Sherri C. 2016. The Development of Children's Concepts of Emotion. In Handbook of Emotions, 4th ed. Edited by Lisa Feldman Barrett, Michael Lewis and Jeannette M. Haviland Jones. New York: Guildford Press, pp. 307-18.

(c)

(C) 2019 by the author. Licensee MDPI, Basel, Switzerland. This article is an open access article distributed under the terms and conditions of the Creative Commons Attribution (CC BY) license (http://creativecommons.org/licenses/by/4.0/). 